\title{
Studies on impurity incorporation in cadmium oxalate crystals grown by gel method
}

\author{
N JAGANNATHA and P MOHAN RAO \\ Department of Physics, Mangalore University, Mangalagangotri 574199 , India \\ MS received 22 September 1992; revised 12 July 1993
}

\begin{abstract}
Aspects of gel growth of cadmium oxalate single crystals doped with monovalent $\left(\mathrm{Li}^{+}, \mathrm{Na}^{+}, \mathrm{K}^{+}\right.$and $\left.\mathrm{NH}_{4}^{+}\right)$and divalent $\left(\mathrm{Ca}^{2+}, \mathrm{Co}^{2+}, \mathrm{Ni}^{2+}\right.$ and $\left.\mathrm{Zn}^{2+}\right)$ cation impurities are discussed. The growth experiments were carried out by single diffusion method. In this paper the effect of composition of the supernatant solution is considered. Rigorous characterization involves determination of composition of cations by employing atomic absorption spectrophotometer and of anions by titration method. The Pauling radius, hydration energy and distribution coefficient of the cations are tabulated and the results are described and discussed.
\end{abstract}

Keywords. Gel technique; impurity incorporation; cadmium oxalate; distribution coefficient.

\section{Introduction}

In recent times much attention has been paid to the role of foreign particles in the crystallization process, for example, in semiconductor industries (de Kock 1980) and in industrial crystallization (Nyvlt 1982). Sometimes, the addition of impurities to these crystals changes their physical properties in specific ways. Because of this, a lot of research is carried out to determine the influence of impurities on crystal growth.

The character of impurity incorporation, the impurity structure of crystals and its changes depending on growth conditions are important both for crystal growth studies and for creation of crystalline materials with a given impurity structure. But hitherto there are relatively few works, especially at elementary level, in which investigation of impurity incorporation and impurity distribution mode in crystals grown in gels is directly connected with growth conditions.

A detailed investigation highlighting the influence of doping with varieties of monovalent $\left(\mathrm{Li}^{+} . \mathrm{Na}^{+}, \mathrm{K}^{+}\right.$and $\left.\mathrm{NH}_{4}^{+}\right)$and divalent $\left(\mathrm{Ca}^{2+}, \mathrm{Co}^{2+}, \mathrm{Ni}^{2+}\right.$ and $\mathrm{Zn}^{2+}$ ) cations on the growth of $\mathrm{CdC}_{2} \mathrm{O}_{4} 3 \mathrm{H}_{2} \mathrm{O}$ single crystals by gel technique is reported here.

\section{Experimental details}

Sodium metasilicate solution (specific gravity $\left.1.04 \mathrm{~g} . \mathrm{cm}^{-3}\right)$ and oxalic acid $(0.5 \mathrm{M})$, 10:8 ratio by volume, was allowed to gel in corning glass test tubes (length $200 \mathrm{~mm}$, inner diam. $25 \mathrm{~mm}$ ). The observed $\mathrm{pH}$ was 3.8 . Gel formation took about six days. A mixture of cadmium chloride and chloride of dopant ion $\left(\mathrm{Li}^{+}, \mathrm{Na}^{+}, \mathrm{K}^{+}, \mathrm{NH}_{4}^{+}, \mathrm{Ca}^{2+}\right.$, $\mathrm{Co}^{2+}, \mathrm{Ni}^{2+}$ and $\mathrm{Zn}^{2+}$ ) solutions was added slowly as the supernatant solution above the set gel. Anala R grade $(\mathrm{CDH})$ chlorides were used as the reagents. The composition of the mixture was varied from $1: 1$ to $5: 1$ by volume. 
The growth conditions were kept constant, except the composition of the mixed solution. Perfect single crystals were observed to grow inside the gel column. After ten days, these crystals were collected by washing with distilled water. Cations were determined by employing AAS (atomic absorption spectrophotometer, Varian Spectra AA-30; accuracy limit in ppm level). The oxalate ion per cent was determined by $\mathrm{KMnO}_{4}$ titration (Day and Underwood 1981) (accuracy limit in 2 parts per thousand) and the number of water molecules estimated by thermogravimetry (Mettler TA-4000).

\section{Results and discussion}

Good quality single crystals were obtained under the given conditions when the ratio of cadmium chloride and the chloride of the dopant ion in the supernatant solution was 5:1. It is interesting to note that with a particular growth condition, all the cations, viz. $\mathrm{Li}^{+}, \mathrm{Na}^{+}, \mathrm{K}^{+}, \mathrm{NH}_{4}^{+}, \mathrm{Ca}^{2+}, \mathrm{Co}^{2+}, \mathrm{Ni}^{2+}$ and $\mathrm{Zn}^{2+}$, enter into the cadmium oxalate crystal as impurities. The typical crystals grown are shown in figure $1 . \mathrm{Co}^{2+}$ doped cadmium oxalate crystals were pink in color while $\mathrm{Ni}^{2+}$ doped crystals were pale yellow. Slight to moderate changes were observed in the crystal morphology depending on the dopant ion. For example, the morphology change was predominant in the case of $\mathrm{Co}^{2+}$ doped cadmium oxalate crystals.

The results of chemical analysis are given in table 1 . It is clear from the chemical analysis that each ion acts as an impurity on the growth of cadmium oxalate. The effectiveness of this process depends on different parameters. In order to measure the amount up to which those ions are incorporated in the crystal under the given conditions of growth, the distribution coefficient

$$
K_{D}=\frac{\left(C_{\mathrm{Me}} / C_{\mathrm{Cd}^{2}}\right) \text { crystal }}{\left(C_{\mathrm{Me}^{2}} / C_{\mathrm{Cd}^{2}}\right) \text { solution }}
$$

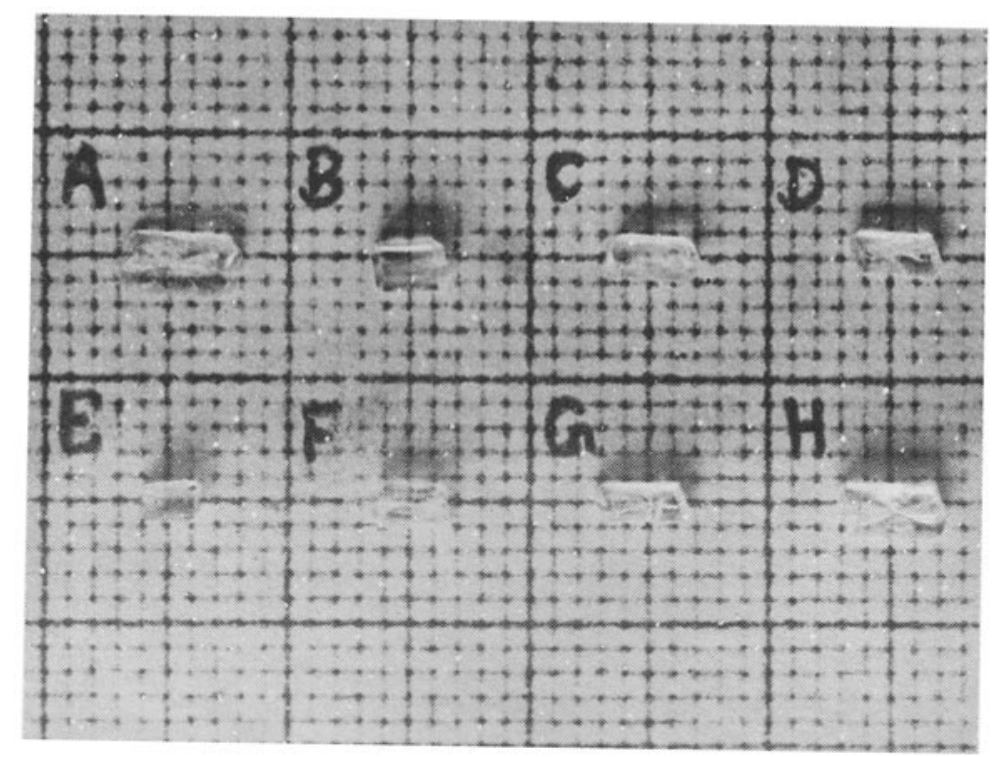

Figure 1. Morphology of cation doped cadmium oxalate crystals. 
Table 1. Chemical composition and size of the crystals.

\begin{tabular}{|c|c|c|c|c|c|c|}
\hline \multirow[b]{2}{*}{ Crystal } & \multirow[b]{2}{*}{ General formula } & \multicolumn{4}{|c|}{ Composition in percentage } & \multirow{2}{*}{$\begin{array}{c}\text { Size } \\
\left(\mathrm{mm}^{3}\right)\end{array}$} \\
\hline & & $\mathrm{Cd}^{2+}$ & Doping ion & $\mathrm{C}_{2} \mathrm{O}_{4}^{2-}$ & Water & \\
\hline A & $\mathrm{Ca}_{x} \mathrm{Cd}_{1-x} \mathrm{C}_{2} \mathrm{O}_{4} 3 \cdot 5 \mathrm{H}_{2} \mathrm{O}$ & $36 \cdot 0$ & 0.3 & 36.6 & $27 \cdot 2$ & $5 \times 2 \times 1$ \\
\hline B & $\mathrm{Co}_{x} \mathrm{Cd}_{1-x} \mathrm{C}_{2} \mathrm{O}_{4} 4 \mathrm{H}_{2} \mathrm{O}$ & $36 \cdot 3$ & 0.4 & $36 \cdot 9$ & $26 \cdot 4$ & $3 \times 2 \times 2$ \\
\hline $\mathrm{C}$ & $\mathrm{K}_{2 x} \mathrm{Cd}_{1-x} \mathrm{C}_{2} \mathrm{O}_{4} 4 \mathrm{H}_{2} \mathrm{O}$ & 35.8 & 0.3 & $36 \cdot 7$ & $27 \cdot 2$ & $4 \times 2 \times 1$ \\
\hline D & $\mathrm{Na}_{2 x} \mathrm{Cd}_{1-x} \mathrm{C}_{2} \mathrm{O}_{4} 3 \cdot 5 \mathrm{H}_{2} \mathrm{O}$ & $36 \cdot 5$ & 0.4 & $37 \cdot 3$ & $25 \cdot 8$ & $4 \times 2 \times 1$ \\
\hline $\mathrm{E}$ & $\mathrm{Ni}_{x} \mathrm{Cd}_{1-x} \mathrm{C}_{2} \mathrm{O}_{4} 3-5 \mathrm{H}_{2} \mathrm{O}$ & $35 \cdot 8$ & 0.3 & $36 \cdot 5$ & 27.5 & $2 \times 2 \times 1$ \\
\hline $\mathbf{F}$ & $\mathrm{Zn}_{x} \mathrm{Cd}_{1-x} \mathrm{C}_{2} \mathrm{O}_{4} 4 \mathrm{H}_{2} \mathrm{O}$ & $34 \cdot 9$ & 0.2 & $36 \cdot 1$ & $28 \cdot 8$ & $3 \times 2 \times 2$ \\
\hline G & $\mathrm{Li}_{2 x} \mathrm{Cd}_{1-x} \mathrm{C}_{2} \mathrm{O}_{4} 3 \mathrm{H}_{2} \mathrm{O}$ & $35 \cdot 9$ & 0.2 & $35 \cdot 7$ & $28 \cdot 2$ & $4 \times 2 \times 1$ \\
\hline $\mathbf{H}$ & $\left(\mathrm{NH}_{4}\right)_{2 x} \mathrm{Cd}_{1-x} \mathrm{C}_{2} \mathrm{O}_{4} 3 \mathrm{H}_{2} \mathrm{O}$ & $35 \cdot 7$ & 0.4 & $36 \cdot 9$ & 27.0 & $5 \times 3 \times 1$ \\
\hline
\end{tabular}

Table 2. Distribution coefficient and hydration energy of cations.

\begin{tabular}{lccc}
\hline Cation & $\begin{array}{c}\text { Pauling radius } \\
(\AA)\end{array}$ & $\begin{array}{c}\text { Hydration energy } \\
\Delta H_{\text {tydration }} \\
\left(\mathrm{kJ}^{\prime} \mathrm{mol}^{-1}\right)\end{array}$ & $\begin{array}{c}\text { Distribution } \\
\text { coefficient } \\
K_{D}\end{array}$ \\
\hline $\mathrm{Li}^{+}$ & 0.60 & -445.22 & 4.652 \\
$\mathrm{Na}^{+}$ & 0.95 & -364.06 & 2.758 \\
$\mathrm{~K}^{+}$ & 1.33 & -303.91 & 1.307 \\
$\mathrm{NH}^{+}$ & 1.40 & -294.94 & 3.207 \\
$\mathrm{Zn}^{2+}$ & 0.74 & -1635.09 & 0.539 \\
$\mathrm{Ca}^{2+}$ & 0.99 & -1426.53 & 0.932 \\
$\mathrm{Ni}^{2+}$ & 0.69 & -1684.34 & 0.668 \\
$\mathrm{Co}^{2+}$ & 0.72 & -1654.44 & 1.037 \\
$\mathrm{Cd}^{2+}$ & 0.97 & -1441.24 & - \\
\hline
\end{tabular}

where $C_{\mathrm{Me}}$ represents the concentration of the ions $\mathrm{Me}^{+}$or $\mathrm{Me}^{2+}$, is determined. The values of $K_{D}$ for various cations are given in table 2 .

Generally the effect of the foreign particle on crystal growth is a complicated process. It may depend on several factors like ionic radii, enthalpy of dehydration, chemical affinity of the competing cations, diffusivity, solubility product, etc. If we assume that the impurity ions substitute for $\mathrm{Cd}^{2+}$ ion in the crystal structure, the incorporation of ions with ionic radii nearer to that of $\mathrm{Cd}^{2+}$ should be favoured because the introduction of such ions results in less geometric problems due to a smaller difference in ionic radius. The Pauling radii of the dopant ions are also recorded in table 2.

As dehydration plays a crucial role in the process of growth and the competitive influence of impurities, it is important to compare the enthalpies of dehydration of $\mathrm{Cd}^{2+}$ and dopant ions. Philips and Williams (1965) reported the empirical formula (valid at $25^{\circ} \mathrm{C}$ ) as

$$
\Delta H_{\text {hydration }}=-699 z^{2} / r_{\text {eff }} \mathrm{kJ} \cdot \mathrm{mol}^{-1} \text {, }
$$

where $z$ is the cation valency and $r_{\text {eff }}$ the effective cationic radius (in $\AA$ ), which is the sum of Pauling ionic radius of cation and anion $(0.97 \AA)$. Using this formula the enthalpies of dehydration given in table 2 were calculated. According to this table, it is expected that ions with lower dehydration barrier (i.e. smaller enthalpy of 


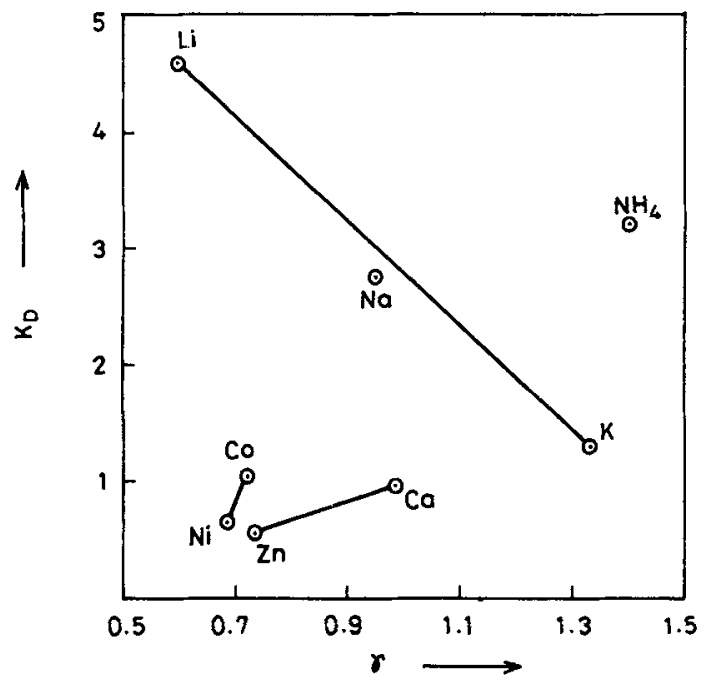

Figure 2. Plot of distribution coefficient vs Pauling radius of the cations.

hydration) show higher distribution coefficient since these ions will be strongly incorporated in the $\mathrm{CdC}_{2} \mathrm{O}_{4} 3 \mathrm{H}_{2} \mathrm{O}$ lattice.

On examination of table 2 , we find that no single explanation is possible for the incorporation of all the eight varieties of cations based on any parameter. Figure 2 depicts a plot of the distribution coefficient $K_{D}$ against the Pauling ionic radii of the impurity cations. It is observed clearly from figure 2 that the dopant cations divide themselves into three groups in their behaviour of incorporation into the cadmium oxalate lattice.

The first group consists of the alkali metal cations $\mathrm{Li}^{+}, \mathrm{Na}^{+}, \mathrm{K}^{+}$, with $\mathrm{NH}_{4}^{+}$being a little exceptional. $\mathrm{Zn}^{2+}$ and $\mathrm{Ca}^{2+}$ form the second group, while the third group consists of $\mathrm{Ni}^{2+}$ and $\mathrm{Co}^{2+}$.

$\mathrm{Li}^{+}$ion, with the smallest ionic radius $(0.6 \AA)$ among the alkali metal ions, has the smallest enthalpy of dehydration $\left(\Delta H=-445 \cdot 22 \mathrm{~kJ} \cdot \mathrm{mol}^{-1}\right)$. Accordingly, the incorporation of $\mathrm{Li}^{+}$is higher compared to those of $\mathrm{Na}^{+}$and $\mathrm{K}^{+}$. The values of distribution coefficients for $\mathrm{Li}^{+}, \mathrm{Na}^{+}$and $\mathrm{K}^{+}$were observed to be inversely proportional to the corresponding dehydration barrier. The exceptional behaviour of $\mathrm{NH}_{4}^{+}$may be attributed to the coordinated hydrogen bond in $\mathrm{NH}_{4}^{+}$.

It is interesting to note that the number of water molecules associated with the lattice increase as the impurity ion is changed from $\mathrm{Li}^{+}$to $\mathrm{K}^{+}$(table 1).

Accordingly, it can be expected that the $\mathrm{Zn}^{2+}$ ion is incorporated more strongly in the cadmium oxalate lattice in comparison to $\mathrm{Ca}^{2+}$ ion due to its smaller enthalpy of dehydration. The results (figure 2 and table 2) show that the incorporation of $\mathrm{Ca}^{2+}$ is higher compared to that of $\mathrm{Zn}^{2+}$. This may be explained on the basis of the relative sizes of these two ions. The incorporation of $\mathrm{Ca}^{2+}$ should be favoured with regard to $\mathrm{Zn}^{2+}$ assuming a $\mathrm{Cd}^{2+} \rightarrow \mathrm{Me}^{2+}$ substitution; due to a smaller difference in the ionic radius incorporation of $\mathrm{Ca}^{2+}$ results in less geometric problems.

On the other hand, the impurity ions $\mathrm{Ni}^{2+}$ and $\mathrm{Co}^{2+}$ have similar sizes and enthalpies of dehydration. The value of $K_{D}$ is higher for $\mathrm{Co}^{2+}(1.037)$ than for $\mathrm{Ni}^{2+}$ $(0.668)$. Explanations in terms of ionic size or enthalpy of dehydration may not be sufficient to explain these results. 
One possibility of solving this problem is to compare the solubility products of these compounds. The solubility product of $\mathrm{NiC}_{2} \mathrm{O}_{4}\left(4 \times 10^{-10}\right)$ must be much smaller than that for $\mathrm{CoC}_{2} \mathrm{O}_{4}$, which indicates that the interaction between $\mathrm{Ni}^{2+}$ and the oxalate ion must be stronger than that between $\mathrm{Co}^{2+}$ and $\mathrm{C}_{2} \mathrm{O}_{4}^{2-}$. Consequently it can be understood that the distribution coefficient of $\mathrm{Co}^{2+}$ in cadmium oxalate is higher.

Our preliminary studies show that there is a change in the unit cell parameter and hence the structure of cadmium oxalate due to the incorporation of these various cations. The detailed structural investigation of these single crystals are in progress.

\section{Conclusions}

The change in colour and morphology of the crystals may be due to the impurity cations as dopants. There is good agreement with the theoretical concept that ions with lower dehydration barrier will show higher distribution coefficient. There is a linear relationship between the Pauling radius and the distribution coefficient for cations belonging to the same group of the periodic table.

\section{Acknowledgements}

We thank Prof. M K Balagopalan, Director, and Mr Francis, Geological Survey of India, Mangalore, for their help in chemical analysis of the samples. We are also thankful to Prof. N C L N Charyulu, Chairman, Prof. Divakara Rao and Ms Vidyavathi, KREC, Surathkal, for their help in thermal analysis of the samples.

\section{References}

Day R A and Underwood A L (eds) 1981 in Quantitative analysis (New Delhi: Prentice Hall) p. 588 de Kock A J R 1980 in Handbook on semiconductors, (eds) S P Keller and T S Moss (Amsterdam: North Holand Publishing Company) Vol. 3, p. 247

Nyvit J 1982 in Industrial crystallization, (eds) S J Jancic and E J de Jong (Amsterdam: Elsevier) p. 253 Philips C S G and Williams R J P (eds) 1965 Inorg. Chem. p. 159 